\title{
Editorial
}

\section{Striving for quality in healthcare services: role of integration}

\section{Sudath K Dharmaratne \& Dewanee Ranaweera*}

Directorate of Healthcare Quality and Safety, Ministry of Health, Sri Lanka

Correspondence: dranaweera90@gmail.com

https://orcid.org/0000-0002-6745-4854

DOI: https://doi.org/10.4038/jccpsl.v26i3.8387

Received on: 28 September 2020

Accepted on: 30 September 2020

Sri Lanka provides free health services to all the citizens at the point of entry. Clearly demarcated preventive and curative health service delivery is a cardinal feature of the health care system of our country. Preventive health service delivery system has been well established since 1925, through which the country has achieved many remarkable health outcomes compared to other countries in the region up to now. Robust disease surveillance mechanisms and high vaccination coverage have contributed to reduction of communicable diseases and we are now facing public health challenges due to epidemiological and demographic transitions, in addition to emerging and re-emerging diseases. Moreover, improvement of healthcare delivery requires a deliberate focus on the quality of health services. Quality of care is the degree to which health services for individuals and populations increase the likelihood of desired health outcomes and are consistent with current professional knowledge. Key elements of healthcare quality include effectiveness, safety, peoplecenteredness, timeliness, equity, efficiency and integration (1).

The different sectors involved in providing healthcare include government sector comprising the curative and preventive institutions, private health institutions and others. Integration of healthcare among different sectors as well as between different units of an institution is very important in providing a high-quality health service to people. Integrated health services mean that the care a patient receives across the healthcare facilities and healthcare providers would be coordinated so that patients get the optimum care in ways that are user-friendly. Even after a patient is discharged from a healthcare facility, options would be evaluated to support patient's care plan and connect the patient with the agencies that offer disease related specific care and other services as needed (1-2).

Integrated health services are of value to almost all even though it is more valuable for certain patients and diseases. With emerging chronic and noncommunicable diseases, more people are living with multiple, chronic, long-term conditions that require coordination of care across all levels and throughout their life course. Continuity of care and its coordination can improve the care experience of people living with such conditions. However, substantial gaps in the coordination of health care exist in countries across the world and Sri Lanka is no exception. A survey of patients with complex care needs in 11 high-income countries found coordination problems, such as test results or records not available at appointment or duplicate tests ordered and providers failing to share important information with each other (1). These challenges and rising patient expectations have resulted in new demands on health care systems to deliver care that is comprehensive and 
continuous rather than fragmented and episodic (3). Integration of health services can play a significant role in fulfilling these demands.

Integration involves multiple healthcare professionals and discussions about the organizational tasks which need to be performed to deliver optimum quality healthcare services. For an example, when National Programme for Tuberculosis Control and Chest Diseases (NPTCCD) pursues their End TB - 2035 Strategy, the curative sector must be able to screen every presumptive tuberculosis (TB) patients (who are having cough for more than two weeks) by examining sputum for Acid Fast Bacilli (AFB) in three consecutive samples. This cohort should go along their care pathway without losing a single patient during follow up until they get cured. Moreover, patients with diabetes and HIV-AIDS are more prone to get TB in their life course. Hence, preventive strategies of the Non-Communicable Disease Bureau and National STD/AIDs Control Programme are also important for NPTCCD to achieve their ultimate goal. Thus, preventive programmes need to work in coordination with other relevant programmes. Another example is the current COVID- 19 epidemic, in which collective activity of major stakeholders such as Epidemiology Unit, Environmental \& Occupational Health Unit and Regional Health authorities is important in deciding the most effective multimodal public health interventions.

Sri Lankan health sector provides integrated care to a certain extent. However, the critical questions are, "is this adequate?" and "do we need better integration in which all major role players work collectively and share their ideas and opinions to create a synergistic effect?" The extent of integration must be set up after agreement of the relevant stakeholders including patient groups. Policy makers have to decide on the optimum mechanisms of health care service integration with multi stakeholder involvement, in order to suit the country context.

Sri Lanka is having a good health care delivery system with certain level of integration. Identifying gaps and improving integrated service delivery in a manner that augments the quality healthcare service delivery and involvement of major role players in our health system are of paramount importance.

\section{References}

1. WHO for Economic Co-operation and Development, World Bank. Delivering quality health services: a global imperative for universal health coverage. Geneva: World Health Organization, 2018. Available from https:// www.worldbank.org/en/topic/univer salhealth coverage/publication/delivering-quality-healthser vices-a-global-imperative-for-universalhealth-coverage.

2. WHO. Integrated health services: what and why. Technical Brief No.1. World Health Organization, May 2008. Available from: https://www.who.int/ healthsystems/technical brief final.pdf.

3. WHO. Technical Series on Primary Healthcare: Integrating Health Services. Geneva: World Health Organization, 2018. Available from: https://www. who.int/docs/default-source/primary-health-careconference/linkages.pdf wwwnc.cdc.gov/ eid/article/26/6/20-0320_article.

\section{Author affiliation}

Dr SK Dharmaratne is a Specialist in Medical Administration and Director, Healthcare Quality and Safety, Ministry of Health, Sri Lanka

Dr D Ranaweera is a Specialist in Community Medicine and Deputy Director, Healthcare Quality and Safety, Ministry of Health, Sri Lanka 